Article

\title{
An Analysis of the Skill Shortage Problems in Indian IT Companies
}

\author{
Suchandra Paul \\ School of Social Sciences, University of Dundee, Dundee DD1 4HN, UK; paul.suchandra01@gmail.com
}

Received: 5 August 2018; Accepted: 10 September 2018; Published: 14 September 2018

check for updates

\begin{abstract}
Skill shortage is a crucial social issue which needs to be analyzed thoroughly in any organization. In this paper, the problems related to the skill shortage are analyzed and possible solutions are provided to deal with the problem of skill shortages effectively. This paper will facilitate in helping the organization to find the right talent for the organization thus removing or decreasing the problem of skill shortages. The paper begins with the importance of skills shortage from a theoretical point of view. The problems associated are highlighted and analyzed. The factors which are an integral part of skill shortages are elaborated. Also, an in-depth analysis is carried out by considering the organizations, Tata Consultancy Services and Infosys as a case study. In the final section, various solutions and approaches are laid down to tackle the problems incorporated with skill shortages.
\end{abstract}

Keywords: skill shortage; social issue; human resource management

\section{Introduction}

A skill shortage is a source of aggravation to firms and, when severe, is likely to affect the quality and quantity related to the output of the organization (Richardson 2007). Skill shortages are associated with the shortages of relevant sufficiently skilled people available in the job market, relative to the jobs that employers are providing (Holt et al. 2010). The skill shortages are due to the unavailability of sufficient people with a specific skill to compensate for the particular demand. Skill shortage is a crucial term used to elaborate a category of circumstances where it is difficult for an employer to detect a worker with potential skills. The criteria of skill shortages differ greatly regarding cause and nature (Careersnz 2015). Obtaining sufficiently skilled employees for a sophisticated organizational economy is an acquainted attention of vast concern innumerable countries. Skill shortage can also mean a shortage in relation to the recent demand of the employees in an organization. Apart from that, a shortage can also be related to some appropriate stated optimal of skills, which presumably may be more distinctly termed to be as skill deficiency (Green and Ashton 2016). The impact of skill shortages in any organization is extensively high and crucial and so it is an issue of great concern. The matter of skill shortages in any organization is a concern for all the leading organizations around the world, and for good reason. If it becomes very difficult to have access to the future requirements, significant gaps in the workforce can seriously affect the efficiency and quality of the working environment in any organization (Fournier 2017).

India is one of the largest employers in the IT sector and services industry. In spite of that, the IT industry is facing a deficiency in available manpower. If this is not urgently addressed, it may have severe impact on organizational growth (Acharya and Mahanty 2007). The prevalence of skill shortages in Indian companies was validated by the research carried out by Murti and Bino (2014). On the basis of the primary data collected from 102 firms, situated in three metropolises-Mumbai, Bangalore, and Hyderabad, the authors identified the phenomenon of skill shortages. Their research reveals that more than half of the companies in India have vacancies which are hard to fill. It was also identified 
that the probability of having skill shortages increases with companies having hard-to-fill vacancy increments with firm dimension. The data extraction reveals that 57 percent of the companies are facing hard-to-fill vacancies in which around 43 percent of the companies are having skill shortages. Also, the information about the existence of skill shortages in Indian information technology (IT) industries was being extracted from various authentic sources such as newspaper quotes, Tata Consultancy Services Limited (TCS) and Infosys Limited (Infosys) annual reports and other important reports which are cited appropriately.

In this paper, the skill shortage issues related to IT industries in India are analyzed. We will consider two top IT companies, namely TCS and Infosys for the thorough analysis. The highest paid sector in India is the IT industries with the range of median gross salary of six dollars per hour. If we compare this with the Banking, Financial services and Insurance (BFSI) sector, it is five dollars per hour (Basu 2016). Recently, it has become well-known to the employers that the appropriate salary structure is a main ingredient for attracting and retaining top talented employees in the companies. Thus, it is an important issue to precisely monitor and analyze the structure of employees with respect to the current trends and make suitable changes where relevant (Ayyar 2017).

TCS is a multinational IT service company which provides consultation and solutions to business-related tasks. The headquarter of the company is in Mumbai, India. It is an important part of Tata Group and exists in 46 countries (TCS Wiki 2018). TCS policy also delivers out bands based on the performance of the employees and therefore one grows in terms of money and designation, which solely depends on the appraisal. Also, the TCS is one of the highest paid organizations in India. Another reputed Indian multinational organization which provides business consulting, IT services and outsourcing is Infosys. The headquarters of Infosys is in Bengaluru, India (INFOSYS Wiki 2018). Infosys offers much to the employees in terms of good salaries, stock and company shares, thus making it to a position of top-notch salary providers in India.

Recent investigation reveals complaints vested on the economic inefficiencies that have occurred from a shortage of skilled workers. Skill shortages are a matter of concern and are widespread with various industrial and occupational groups expressing such concerns (McMullin et al. 2004). Also, skill shortages have a negative effect on production and prevent organizations from meeting demands and utilizing available inputs in an effective manner. IT is an example of a generalized purpose technology which has the capability to initiate a significant role in economic growth and as other dimensions of economic and social development (Singh 2016). Haskel and Martin (1993) developed a simple model that illustrates how skill shortages minimize productivity. So it as an important area of investigation from the viewpoint of organizational growth and productivity. IT organization is a manpower intensive organization and its development relies broadly on the availability of skilled workers. So, the looming skilled workers' shortage crisis in the Indian IT industry can definitely downgrade the organization path towards growth (Acharya and Mahanty 2007). The various HR related issue including the phenomena of brain drain which are primary causes of skill shortages are highlighted. Based on these issues, the effective solutions are provided to deal with the problem of skill shortages. The paper has highlighted the scenarios leading to such a crisis and possible ways of handling skill shortages issue in an effective manner.

One of the important factors associated with the problem of skill shortage is the recruitment and selection process. In this process, human resources (HR) personnel identifies talented and skilled employees for the organization. Employee retention is extremely important for an organization for retaining skilled employees for a longer duration. Also, there are other influential factors such as employee compensation, reward management, employee training and geographical location which have a great impact on skill shortages. A detailed analysis of all of these issues is carried out in Section 2.2. The phenomena of "Brain Drain" has a great influence on skill shortages issue. People with superior skills tend to move to other countries with greater opportunities thus creating the problem of skill shortages in the home country. The impact of such a brain drain on the issues of skill shortage is explained in Section 2.4. Two reputed IT industries in India, TCS and Infosys, are considered in this 
paper as a case study. A brief review of the company profile is illustrated in Section 3. In Section 4, some crucial skill shortage issues in TCS and Infosys are illustrated. Some solutions are provided that may be helpful to deal with the skill shortage issues effectively. Also, the strategy incorporated by TCS and Infosys in mitigating skill shortages are illustrated. New HR policies that will facilitate in minimizing skill shortage problems in TCS and Infosys are stated in Sections 4.3 and 4.6, respectively. In Section 5, a general discussion for skill shortage mitigation in TCS and Infosys are presented. The conclusion of the paper is presented in Section 5 .

\section{Theoretical Evidences and Causes}

\subsection{Skill Shortages: The Definition and Importance to an Organization}

In general terms, the importance related to skill shortages increases when the intense growth of the economy has been uninterrupted for several years. In the primary recovery phase maintaining a downturn, the demand related to labor can be attained by slack labor. Once slack labor attains employment, then shortages appear as a problem. However, the economic cycle does not have the same impact on all jobs. It is not necessary that shortages have to be countrywide in terms of scope. It can prevail in a particular area of a country, also in the industrial field or maybe in a sub-talent related to an occupation. The skill shortages can be a hindrance to the growth of the economy (Cohen and Zaidi 2002). There is much evidence which validates that the requirement for skilled employees has been outrunning the supply for some time now (Leuven et al. 2004). Few skills are only utilized in particular industries, for example, a shortage of one specific pattern of labor will create problems in some organizations, but will have limited or zero impact on others. It is obvious that recruitment in the certain organization is lagging due to the lack of skilled labor, even in the condition when there is an evidence of labor-presumably highly qualified, but with insufficient skills (Stevens 2007). Any problems related to skill shortages experienced by sector, have a serious effect on the HR firm policies as well as on the recruitment and retention strategies they undergo, particularly on the issues related to training and development activities (Clarke and Herrmann 2007). The survey conducted by Organization for Economic Co-operation and Development (OECD) (OECD 2008) elaborates that the world will face the risk of skill shortages which will hamper the growth of the future economy.

\subsection{Important Factors Associated with the Problem of Skills Shortage}

\subsubsection{Recruitment and Selection}

In the recruitment and selection process, talented employees are identified so as to get well fitted with the concerned hiring companies. It is generally a complicated and costly process. The role of the employers is important, as it is necessary to keep close attention to the behavioral criteria of the employees during the recruitment and selection process (Ahmad and Schroeder 2002). The main approaches of recruitment and selection process are demonstrated in Figure 1 (Roberts 1997).

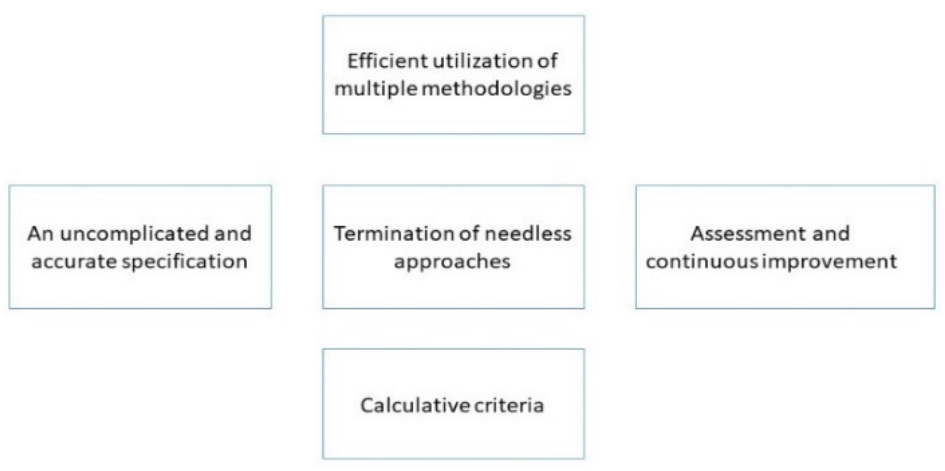

Figure 1. Recruitment and Selection Process. 
Generally, five percent of the world workforce is assumed to be under-qualified with respect to their job role thus influencing the efficiency and the total productivity of the companies they are engaged with. Recruiters should ideally connect skills and recruit employees who are well suited for the post. In several cases, either due to poor selection or recruitment pressure, recruiters have less or no option but to recruit people with limited skills. The stages of the recruitment process start with prospective employer identification, that is, who is actually looking for a job. The next step is the job analysis by the employer and illustration of the key specifications for the job. Candidates will then be verified as being on par with the job requirements and consequently screening process will be carried out. The interview process is then carried out to test and access candidates' motivation and their abilities for the justification of the post applied. The recruitment process is finalized by offering the job to the candidates and offering them appointment letters holding the policies and advantages of the organization (Johanette Rheeder 2017). Apart from that, the other two important factors that can affect the recruitment and selection process are cutoff score and bulk recruitment.

\section{Important Issues Associated to Recruitment and Selection (Cutoff Score and Bulk Recruitment)}

Cutoff scores are used by managers in several organizations as it facilitates making decisions regarding the selection of candidates. In several occasions, the cutoff scores are selected based on suitable criteria and sometimes it is set arbitrarily which may affect the selection process. Setting a too high cutoff score may result in the high amount of rejection of the candidates who may be capable enough to do that particular job (Cascio et al. 1988). The cutoff score is a norm which employers establish in order to set a minimum level to judge the ability of a candidate. Generally, the candidates who secure above the cutoff score are treated as equally qualified. The main drawback of this approaches is that it minimizes the efficiency of the selection process by considering the candidates with various skill sets equally (Iresearchnet 2015).

Bulk recruiting and hiring process requires coordination throughout the HR department. There is a specific role or function associated with all HR staffs and so recruiting new employees in one solo event becomes chaotic. HR staffs feel that inefficiency incorporates during the massive hiring process (Mayhew 2017). Also, bulk recruitment may result in the shifting of all skilled employees to a particular company thus making it difficult for another company to recruit talented employees. Bulk recruitment generally happens in one particular day and it provides employment to a large number of candidates thus creating an issue of skill shortages for other companies. This complexity can be dealt with by analyzing the theory of Porter's five forces model. The implementation of Porter's theory, particularly the component "Competitive Rivalry" facilitates identifying the competition between two organizations in terms of bulk recruitment. Porter's five competitive forces are depicted in Figure 2 (Grundy 2006; Dobbs 2014).

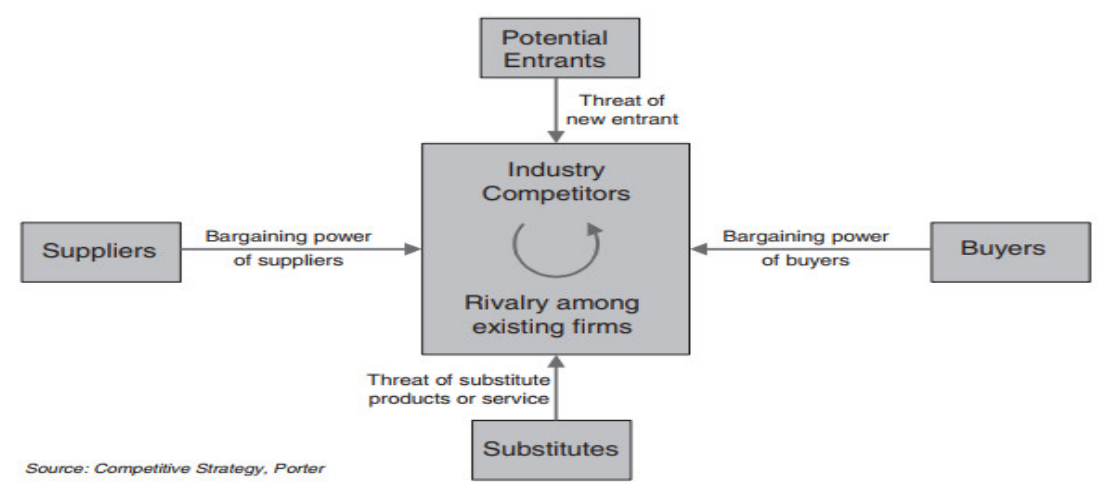

Figure 2. These forces determine industrial profitability (Grundy 2006).

Competitive rivalry depicts intense rivalry, where companies can attract customers with aggressive price cuts and high-impact marketing campaigns. Also, in markets with many 
rivals, suppliers and buyers can go elsewhere if they feel that they are not getting a good deal (MindTools 2018). This concept can be utilized to plan the strategies of recruitment policies, which will attract the candidates to attend the recruitment drive of particular companies. For example, on the same day, two organizations may carry out bulk recruitment drive. The candidates will attend the recruitment drive based on the company profile, facilities provided, salary, and job satisfaction. So, a company recruitment policy is under continuous competition to provide the best, as well as to attract employees for recruitment and selection procedure. So, a properly planned and well-balanced selection and recruitment scheme can handle the problem of skill shortages with a higher success rate. It is necessary to highlight the important theories of recruitment and selection for analyzing the situations of skill shortages.

Essential Theories on Recruitment and Selection

Brewster et al. (2011) illustrated that the challenges for HR business partners in dealing recruitment and selection for an international organization differs with the country, but a common requirement is the question of the way to validate rigor as well as consistency across operations in many diversified cultures, business markets, and labor markets. The Devanna Model illustrates that a successful Human Resource Management (HRM) needs the utilization of a coordinated and coherent set of HR policies that include recruitment and selection.

Sparrow and Hiltrop (1994) proposed that recruitment and selection processes should be utilized to achieve the following goals:

1. To extract present and future staffing requirement by using job analysis technique and planning of HR.

2. Incrementing the pool of applicants at minimal cost.

3. To enhance the achievement rate associated with selection process.

4. To increment the probability factor related to subsequent retention.

5. Encouragement of self-selection process by utilizing realistic job preview.

6. Validation of responsibilities as well as legal and social obligations.

7. To increase the efficiency of organizational and individual related approaches.

8. To compute the effectiveness of various labor pools.

The four main approaches for selection as stated by Brewster et al. (2011) is illustrated in Figure 3:
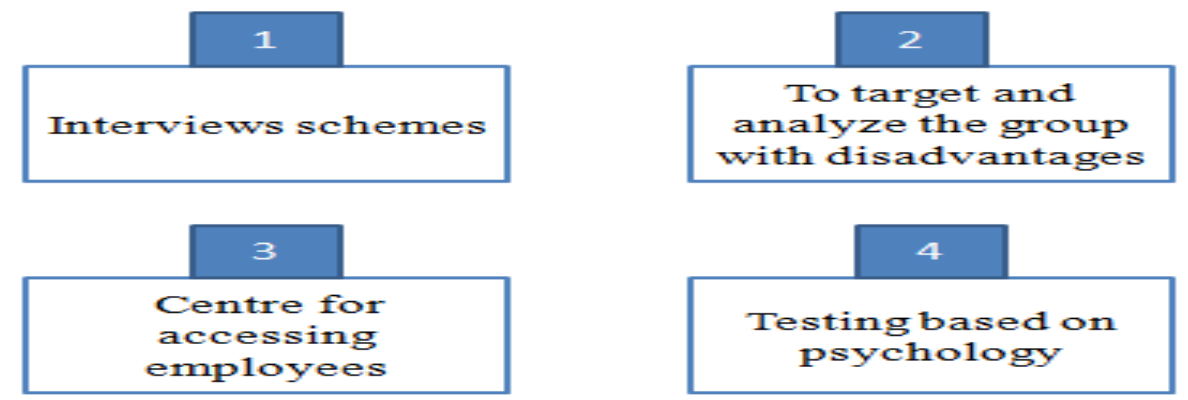

Figure 3. Brewster Approaches.

\subsubsection{Employee Retention}

Employee retention is related to the several policies and practices which motivates the employees to stick to an organization for a longer duration. Every organization invests time and money in developing a new employee to make him ready for the corporate world and bring him to level with the existing employees. The organization suffers a great loss when such an employee leaves the organization once they are properly trained. Management should apply various schemes and approaches to retain the particular employees who are very much important to the system and is 
renowned to be great contributors (MSG 2017). Staff retention processes also include the procedure of training and development. In a job market that is increasingly facing a shortage of well-qualified candidates and with ever-increasing vacancy levels, it is very crucial to ensure the retention of existing employees (Walters 2016). So, employee retention is an important factor which can beat the problem of skills shortages. The essential theory associated with employee retention is illustrated below:

Essential Theory on Employee Retention

Dowling et al. (2008) identified five objectives a multinational company should lay down for designing its international rewards system:

(1) The policy should apply strategic approach thus helping the organization to extract its listed objectives.

(2) The laid down policy should help the company to recruit and retain the staff it requires, specifically the most important staff for its operations.

(3) The policy must be efficient, effective as well as it should reflect the institutional environment in which the organization and its employees must work.

(4) There should be a scheme for the consistent policy having equality requirements of the organization.

(5) The excessive burdens related to administration should not be involved.

\subsubsection{Other Important Influential Factors}

\section{(a) Employee Compensation}

Employee compensation is associated with the benefits such as cash, vacation etc. which are received by an employee in return for the services they provided to the organization. The compensation for the employee is considered to be one of the largest expenditures for any companies. The type of compensation granted to the employees are listed in Table 1 (Study.com 2017).

Table 1. Types of Compensation.

\begin{tabular}{ll}
\hline \multicolumn{1}{c}{ Present Benefits } & \multicolumn{1}{c}{ Future Benefits } \\
\hline Cash compensation which includes wages or salaries & Various plans linked to retirement \\
\hline Schemes regarding paid health insurances & Life insurance \\
\hline Paid vacation and sick leaves & \\
\hline
\end{tabular}

If we consider all these aspects, the wage is an important criterion that affects skill shortages. The two approaches by which skill shortages might increase wages (Booth and Snower 1996) are that:

(i) Skill shortages are a leading path towards a minimum number of skilled workers; hence organization may bid up wages for the recruitment and retaining skilled labor.

(ii) It is great advantages for skilled workers as skilled shortages made them lean towards a heavier bargaining position while considering bargaining over wages.

In case the wages are higher in areas where the provision of skilled labor is much more, reflecting the disparity in human capital, then the effect of the comparative wage may also be biased (Haskel and Martin 2001).

(b) Reward Management

The main area of reward management are strategies, policies, and processes which are essential to validate the work and effort of the employee towards the company and are recognized in terms of both financial and non-financial means. It deals with the design, execution, and maintenance associated 
with the reward systems and its main aim is to meet the requirements of both the organization and stakeholders. The main intention of the reward management is to reward people appropriately, with equality and maintaining a consistency at par with their value to the organization which is done to further the achievement associated with the strategic goals of the organization (Armstrong 2007). Reward management not only deals with pay and the benefits of the employees, it is also evenly concerned with non-financial rewards such as identification, learning and development opportunities as well as increased job responsibility (Kerr and Slocum 1987). The main intentions and roles of reward management are (Iskandar 2015):

(a) To maintain and initiate workforce preferred behaviors.

(b) Strengthening the overall business strategy and validation of organizational success.

(c) To be cost reliable and effective.

(d) The incremental approach towards employee's commitment to an organization taking into consideration productivity, the standard of work and competitiveness.

(e) The benefits and other remuneration should be as par the industry standards.

(f) To reward people on the basis of the value they developed.

(g) The reward practices should go hand in hand with both companies' goals and employee values.

(h) To provide motivation and develop a policy of retaining the skilled and competent people.

(i) To support the progress and growth of a performance culture.

(j) To create a favorable environment in order to nurture positive employment relationship.

There is a significant impact of organizational reward management strategies associated with the issue of skill shortages (StudAids 2013). In order to provide young generation with the knowledge they need, there is a requirement of vast changes in the quality of careers advice in schools, so they are more aware of the opportunities and rewards of working in primary areas which face skills shortages (Jozwiak 2014).

\section{(c) Employee Training}

The training of the employee is a very important stage and is strongly connected to the skill shortages problem (Playfair 2016). Employee training and development is a vast terminology covering several types of employee learning. The training programs help the employees to gather certain knowledge and skills in order to improvise performance in their current roles. The training and development programs with good content and scope help organizations to retain the right employee and help in profit growth. As the competition for top talents becomes supremely competitive, the training of the employees along with the programs for development becomes more important and significant. The important advantages associated with the employee training are demonstrated in Figure 4 (ALLENCOMM 2017).

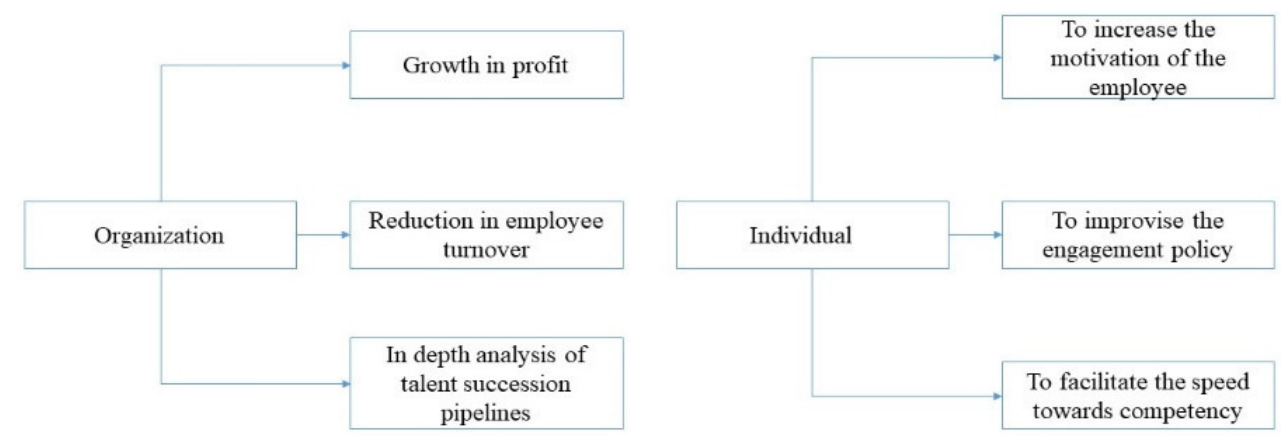

Figure 4. Employee Training.

It is very important that companies take the initiative in training employees in order to fill the middle-skills gap which is crucial to minimize the skill shortage problems (Kochan et al. 2012). 
An efficient training department will also take important steps by laying down the partnership with the other departments in the company in order to keep updated on recent requirements as jobs change (Freifeld 2017). In spite of the reasons or the level of commitment to the approach, the requirement for worker training has increased in an unparalleled way in recent years (Hughey and Mussnug 1997).

\subsection{General Way of Addressing Skill Shortage Problems in IT Company}

The general way of handling skill shortage problems is categorized in the following ways (Livingston 2013):

(a) Re-invent

The companies should follow innovative strategies to run their businesses by considering ideas for developing flexible operating models, organizational structures, as well as career paths, focused on skills rather than business strategies.

(b) Re-evaluate

It is a requirement for a company to identify that what skills their employees hold. All surveyed executives undergoing a gap in skills revealed that they lack the capability to track and measure skills within their company.

(c) Recruit

In order to search a suitable match for particular job description, it is necessary to find novel hires which can demonstrate a capability to learn a particular role or skill as well to match with the culture of the companies. It is necessary to implement internal training programs in order to help new employees acquiring or strengthening the skills which are required for the job.

(d) Realign

It is important to take into consideration the skilled employees who are in low demand in one organization to work in sectors and geographic locations where the requirement for their talent is high.

\section{(e) Collaborate}

It is a crucial step to work with other industry players as well as educational institutions for building a pool of skilled employees and to distribute the costs and risk of validating training programs. This will facilitate the organization to reach a vast audience of skilled workers.

\subsection{Brain Drain Phemonena and Skill Shortages}

Brain drain is a phenomenon in which people having superior skills, degrees, and potential leave their countries and move to other countries for better opportunities. One of the crucial issues of brain drain is associated with the fact that when the students from the underdeveloped countries move to the developed countries for education and do not return to their home countries after completion of studies (Baruch et al. 2007). The description of the brain drain in terms of skill loss is stated by Bushnell and Choy (2001). According to the authors, the word Brain defines skills, competency or attribute which are associated with potential assets. The word Drain signifies the rate of exit which is at the greater level in comparison to the normal rate. India suffered a high rate of brain drain through the 1960 s to the 1990s. Every year graduates, especially from the stream of engineering and sciences, leave India to pursue post-graduate education and research in abroad, the United States being the top in the list. For a long time, Indian students have been considered to be the highest among foreign students in U.S. universities. In the last ten years, a large number of Indian students flooded the universities across U.K., Australia, and Singapore (Singh 2013). In search of better rewards for their talents and efforts, 
the young skilled Indian labors move to other countries and this is one of the prime reasons for skill shortages in India. Through the context of Purchasing Power Parity (PPP), average wages for a person in the US is more than double in the IT sector. Whether employee wages is the only reason why skilled labor migrate to foreign countries? The answer is no as there are other important issues. The quality of higher studies in India is another reason for pushing the brain drain phenomena. Although India has developed much in terms of providing primary education to all children, it is lagging behind in providing quality higher education (Mukunthan and Nagaraj 2017).

A hypothesis laid by Baruch et al. (2007) can contribute significantly to the mitigation of brain drain phenomena which will have a positive impact on the skill shortages problems in IT industries:

1. The superior level of support foreign students receives from their associates belonging to the home country, higher will be the tendency of the students to return to their home country.

2. The labor market has a strong effect on brain drain. A weak labor market in the home country and a strong labor market in the host country will have an impact on the decision of a foreign student, whether to stay in the host country after their studies or return to their home country. So the improvement of labor markets is important in mitigating brain drain crisis.

3. The higher level of Protean Career concept will affect a higher tendency on students to stay in the host country and will contribute to the minimization of brain drain problems.

Tackling the "brain-drain" might honestly be trying to address the signs of the constraints rather than its root causes. It is more crucial to analyze the reasons of brain drain, which are linked to problems associated with the mismatch between supply and demand, the time taking recruitment process in job selection, inferior working conditions, low wages, quality of life or uncertainty about the future of the home country. In many growing nations, abject political management, which ends up in the deep monetary crises that spark an exodus of already scarce skills, is not always uncommon. The self-imposed costs by developing countries make a hard time for the emigrated skilled employees and sometimes even targets their skilled ethnic minorities (Kapur 2017). Sarma and Krishna (2010) revealed that range of public policies in the 1980s and 1990s has given a significant increase to the software industries. These policies gathered significant dynamism which compelled thousands of software professionals to return back to the home country for establishing micro, small and medium enterprises for taking advantage of liberal government policies. A skilled professional is no longer attracted by better job conditions in foreign countries because there are world-class facilities prevailing in India. Thus, dual situations of job opportunities, as well as the presence of the world's leading IT organizations in India, are acting as a motivation factor for the skilled labor for returning to their home country. It also has been identified that the skilled employees living abroad for a longer period of time earning a good salary have the tendency to return to their home country for family reasons (Singh and Krishna 2015). Extensive research revealed the fact that individuals who came back from foreign countries were compelled to carry out some economic reforms and economic growth in India. There are several factors which led to the changing the minds of skilled labors and made them return to their home country, India. These factors are strong family ties, the growth of Indian economy and access to local markets. It also can be concluded that the entrepreneurial situation in India is gaining momentum and the highly skilled labors leaving in abroad are having a track on the changes and also returning to India (Zagade and Desai 2017). Saxenian (2005) illustrated that high-skilled migrant's shifts skills as well as resources from organizations in a mature industry cluster to organizations in an emerging industry cluster. Through their experiences in mature industry clusters, high skilled migrants' extracts high-level skills, develops industry contacts, and build reputations. There is a growth of IT industries to a significant extent in the last decade. This scenario can be supported by the concept of brain circulation, which has overcome the problem of brain drain regrading students migrating for studies in other countries (Xiang 2001). 


\section{Fact and Figures of IT Companies: TCS and Infosys}

\subsection{TCS}

TCS is one of the largest Indian organizations considering the market capitalization ( $\$ 80$ billion). TCS is recently ranked among the 'Big 4' most important IT services brands in the world. In the year 2015, TCS was ranked 64th overall in the ranking of Forbes World's Most Innovative Companies thus making it the highest-ranked IT services in India (TCS Wiki 2018). Tata is also one of the most trusted brands in India which is ranked at 5 in the 2017 list of Forbes India most trusted brands (Venkatesh 2017). TCS employees have very high job security. TCS employees are semi-government employees in the IT sector, as they work less in comparison to other IT companies thus adding to the superior comfort level and family life ultimately adding to high retention rate (Kurup and Vageesh 2017; Thimmaya 2014). TCS allows the employee to choose their preferred locations (Quora 2016) and it has many privileges for female employees (Sites TCS 2017). Training conducted in TCS is much easier (Quora 2017; Patel 2014). In terms of geographical locations, TCS offices are mostly inside the city (AbhiSaysTCS 2017). All the locations mentioned in the reference are within the township range.

\subsection{Infosys}

Considering 2016 revenues, Infosys is the second-largest Indian IT service provider. Infosys market capitalization was recorded at $\$ 34.38$ Billion on 12 January 2017 (INFOSYS Wiki 2018). In terms of the dollar it revenues grew during the year by $9.1 \%$ to the US $\$ 9501$ million in 2016 and in constant currency terms, revenues grew by $13.3 \%$. The flow of cash was superior with liquid assets of US $\$ 5202$ million (Infosys 2017). Interbrand report (2016) reveals that Infosys is ranked 7th on the list of best Indian brands. Infosys provides a top notch in job training (Varma and Ravi 2017). The Infosys training center is considered the world's largest corporate training center. It gives good life and flexibility while training. Mysore campus is the training center which offers a lot to its employee (Infosys Training 2013). For learning novel technologies as well as for rapid learning and growth, Infosys might be better placed than TCS because TCS has more government projects whereas Infosys has more foreign projects consequently more onsite opportunities. If we compare with TCS, job security is less in Infosys as many employees lose their job after the training process (Ayyar and Rao 2017). In terms of geographical locations, Infosys has their offices far away from the city (AbhiSaysINFOSYS 2017). All the locations mentioned in the reference are far from the township range. Currently, Infosys offers better salary ranges for its new recruit in comparison to TCS (Interband Report 2016). In terms of market and process, both the organization is good. Both the companies stress on training related to:

1. Soft Skills

2. Activities related to team building.

3. Training based on generic which covers areas like C, DS, oops, OS, SQL.

4. Stream-related training which is related to Net/Java/Mobile applications/Finacle/Hadoop.

Infosys and TCS are moving with the same trend considering the most essential fundamental shift in the organization and approaches towards automation and artificial intelligence (Saurabh 2016). An extensive review of both the companies gives the following conclusions (Olivia 2011; Recomparison 2017; Diffrenceinmajoritindustries 2011) as illustrated in Table 2. 
Table 2. Organization Comparison.

\begin{tabular}{|c|c|}
\hline TCS & INFOSYS \\
\hline $\begin{array}{l}\text { It stresses on hiring fresh graduates from the reputed university } \\
\text { in India. }\end{array}$ & $\begin{array}{l}\text { It also stresses on hiring new graduates but it has } \\
\text { been giving jobs more aggressively of late as it is in } \\
\text { an expansion face. }\end{array}$ \\
\hline It is more concentrated towards BPO path. & It is reputed for its excellent consultancy services. \\
\hline $\begin{array}{l}\text { It is more involved in IT related work associated with the } \\
\text { government sector to be mention as to provide software } \\
\text { assistance to banks as well as healthcare industries. }\end{array}$ & $\begin{array}{l}\text { It is more reputed for extracting big deals from } \\
\text { foreign clients. }\end{array}$ \\
\hline $\begin{array}{l}\text { It provides cheaper IT related solutions to the client in } \\
\text { comparison to Infosys. }\end{array}$ & It provides superior quality than TCS. \\
\hline The workload is comparatively lesser. & The workload is higher than TCS. \\
\hline $\begin{array}{l}\text { It lacks in the department of promotion process of } \\
\text { the employees. }\end{array}$ & The promotion process is well approached. \\
\hline TCS infrastructure is good but needs improvement. & $\begin{array}{l}\text { It has a much better infrastructure in comparison } \\
\text { to TCS. }\end{array}$ \\
\hline $\begin{array}{l}\text { It has good work culture but needs improvement in comparison } \\
\text { to Infosys. }\end{array}$ & $\begin{array}{l}\text { It is superior in a matter of work culture and } \\
\text { professionalism. }\end{array}$ \\
\hline
\end{tabular}

\section{Analysis of IT Companies from Skill Shortage Perspective: TCS and Infosys as a Case Study in Indian Sector}

\subsection{Some Important Issues Related to Skill Shortages in TCS}

Issues: TCS have a difficult procedure for the recruitment and selection of the prospective employee. TCS management strongly believes in the policy that the company success and achievements is directly connected to the level of the employee working in the organization and so they are very cautious in selecting suitable employees. The recruitment executive mainly searches for the positive attitude in the candidate along with good technical knowledge (Patel 2013).

The main sources of recruitment and selection are:

1. Promotions associated internally as well as internal introductions, which are occasionally favorable for moral issues.

2. Officers associated with careers.

3. Appointment related boards of the University.

4. Offices and officials for helping the unemployed.

5. Utilization of advertising aid or the use of various local media.

The process followed by TCS for recruitment and selection is simple and not rigorous. The selection process involves simple process such as (Geeks for Geeks TCS 2017):

(a) Written round.

(b) Technical round.

(c) Managerial Round.

(d) HR Round.

Moreover, TCS has a policy of bulk recruitment from the university and colleges of India. Bulk recruitment contributes to the problem of skill shortages. Recruitment is considered to be central to any management process. Recruitment process failure can lead to difficulties for any company arising an adverse effect on its profitability and unsuitable levels of staffing or skills. Inappropriate recruitment policy can give rise to labor shortages, problems in management decision making policy (UK Essays 2015).

TCS incorporates a limited scheme for employee retention (Jose 2013). TCS has no appropriate evaluation scheme for new recruits. Employees encounter trust issues occasionally with project 
management thus losing interest in work. A normalized pattern exists in the company of hiring a resource at a higher package but it fails to keep even the critical resources associated with their payroll due to constraint in the packages. There exist grievous issues such as corporate politics and conflicts between employees and managers or with immediate bosses which lead to frustration among employees. This type of situations leads to not so good performance among employees, poor working environment, which ultimately results in the separation of the employee from the company. There have been some instances of corporate conflicts within TCS (Shah 2016; Krishnan 2016). A report by New Delhi Television Limited (NDTV) Profit, 2015 suggests that the employees are quitting the job from TCS more than ever before (Sinha 2015).

Solutions: The simple and straightforward recruitment process could be improved by incorporating psychological tests and subject-based personal interviews. Recruitment is different from the normal selection process and requires management decision-making capabilities and vast planning to implement the most suitable manpower. Successful recruitment methodology includes a thorough analysis of job and the situations of the labor markets as well as interviews and psychometric tests to validate the superior capabilities of applicants. Bulk recruitment should be avoided as the process of selection is done in a span of one day where 2000 to 3000 candidates are recruited, for obvious reasons the process degrades and the candidates with fewer skills are recruited. There is a requirement of a thorough investigation of the vacancies in order to have a clear picture of the job requirements and the quality of the person fit for the recruitment. Then it will be feasible to attract suitable applicants for the required position.

The factors like internal promotion as well as generous and relevant benefits are considered to be the important attributes in retention and high employee satisfaction. Retention criteria validates that organizations make a relatively small contribution to set up internal firm labor markets except for employees but where they do, this scheme has a significant impact on retention. Training and development programs should be given due importance for establishing training needs, appraisals and setting up exit interviews which should be carried out on an informal basis. TCS should give more time for creating formal methods which may include the utilization of toolkits and other validated HR staff retention schemes. Retention schemes should involve superior infrastructure, freedom of the employee to work in its own way and style, frequent meeting between employees and the incorporation of the new idea without fund limitations. It is important to find the reasons for why a job vacancy arises. It may be that the previous employee left due to problems in the business and unless these issues are resolved, the new employee will likely be unhappy too.

TCS should also bring into the scheme an employee training approach based on thoughtful and serious planning. A superior level of attention should be concentrated on detail and desired outcomes. The problems come into action when there is a lack of a coherent foresight with respect to the level of training is required to make it done and how those goals will be measured and rewarded. Training requires a vast amount of commitment; it is very time-consuming as well as demands relentless and ongoing support. The dedication required to conduct high-level employee training is adequate.

\subsection{What Is TCS Doing to Minimize Skill Shortage Problems?}

TCS currently follow the approach of looking at the profiles of candidates with less than one year, then at candidate having 1-3 years of job experience and also those with 3-5 years of job experience. The company is carrying out investigation about the type of engagements the people were recently involved and what type of job they were required to carry out. In this way, the organization is following a systematic effort of investment and training employee thus building their competencies. The organization has understood that it is a requirement to involve employees in extracurricular activities. TCS has set up a well-planned month-on-month calendar that was worked out and giving opportunities to TCS employee to engage themselves and develop their abilities. The TCS has a superior rotation plan to shift employee across various geographical locations and technologies. 
The three innovative strategies brought into action by TCS are; engaging employee at various levels, providing updated technology domain and ability to move across multiple geographies helped to maintain employee motivation high as well maintain high retention (Bussiness Line 2007). At TCS, management has developed an environment that relies on individual aptitude, talent as well as interests. These approaches helped to promote cross-domain which facilitates the employees with several opportunities in order to function across various industry verticals, service practices, and function related domains as well as different technology platforms (Rawat 2013).

\subsection{New HR Policies by TCS to Mitigate Skill Shortages Problems?}

The Corporate Sustainability Report (2017) of TCS reveals the new HR policies which may be very essential to mitigate the skill shortage problems. The policies are listed in a sequential manner as the following:

\subsubsection{Talent Acquisition Policy}

The talent acquisition strategy in TCS involves the partnership with academic institutes. The Academic Interface Program (AIP) launched by TCS to maintain a strong coordination and relationship with worlds top universities. The student engagement portal named Campus Commune facilitate students to organize with their peer groups in order to carry out digital learning through webinars, educational videos and posting of blogs by experts in several areas, thus helping them to be trained for professional life. For identifying excellent talents, program contests such as TESTimony, EngiNx, GameOn, and CodeVita are organized.

\subsubsection{Talent Diversity}

The talent acquisition strategy implemented by TCS has resulted in superior diversity associated with gender, locations as well as various discipline. TCS is considered to be the largest employer for the woman. The organization also introduced potential policies such as parental leave, women employees' security, a mentoring scheme for young women, discussion group for women, a special leadership program for women, workshop on parenting. TCS was named as one of the UK's leading employers for women in The Times Top 50 Employers for Women.

\subsubsection{Talent Development}

To enhance the capability of entry-level managers, a new developed Leadership Development Program (LDP) is launched. The initiative program for enhancing the capabilities of mid-level women managers was a new scheme by TCS and is already showing good results. Initiation of special training for the employers visiting first time to a new country. Also, language training is being offered to employees in order to be proficient in English and 11 other foreign languages as per the requirements.

\subsubsection{Competitive Compensation}

TCS is regularly benchmarking the compensation plans and benefits with peers for ensuring competitiveness. TCS provides skill-based allowances for employees having specialized skills and it motivates the employees to be in tune with the competition thus profiting organization as well as themselves. Compensation layout is carried by prevailing practices in each country it operates.

\subsubsection{Career Management}

The program CareerHub is a platform designed to captures employees' career goals and supplies services related to mentoring. The selection of the mentor for the program is relied on the employees based on their skill sets. Another program named Inspire launched to motivate and provide fast-track career progression to high-potential employees. To realize the potential of senior leaders, a structured coaching program is also launched. 


\subsubsection{Talent Engagement}

Programs such as Knome, KnowMax and GEMS are introduced for social collaboration within companies as well as for learning and sharing ideas. It also supports the scheme for awards and recognition. For proper bonding of employees with the organization, the program Maitree was launched which also promotes work and life balance thus improving employee retention.

From the HR policies and various initiatives of TCS, it is quite relevant that TCS is trying hard to mitigate the problem of skill shortages. Apart from this, the various solutions provided should be given due importance and can be incorporated in the TCS policies to mitigate the problem of skill shortages to the higher extent. TCS updated policies do not include psychological tests and subject-based interview. Also, brainstorming sessions of employers with the managers need to be implemented. The following important points should be given due consideration:

(a) TCS is stressing more on the profiles based on years of experience, instead should focus more on the role of the employee and their contribution in the previous organization in case of experienced candidates.

(b) For the fresh candidate, TCS is selecting them by common interview process, instead, they should focus on the specific IT skills by verifying their skills certificate from private education centers and should be interviewed on the specific skills.

(c) TCS is motivating and grooming the candidates based on their skills and aptitude but most important is the development of the counselor section for counseling the employees in case of grievances or management related issues.

\subsection{Some Important Issues Related to Skill Shortages in Infosys}

Problems: Infosys strictly follow a very high standard process of recruitment and selection for people in their company. All graduate and postgraduate students are eligible for recruitment and selection process, only if they have secured 70 percentages of marks throughout. The student who has already attended the recruitment process in the past 9 months is not eligible. The written process of recruitment is very difficult giving more stress to reasoning aptitude. Infosys also receives a large number of candidates request for job interviews thus making the process hectic and more importantly becomes difficult to recruit the desired candidate out of the large pool of candidates. So, there is a requirement of sophisticated screening process so that right candidate with specific skill is called for interview. In Infosys the recruitment and selection rounds mainly stressed on:

(a) Online based Test

(b) General technical Round

(c) HR Round

The online test for Infosys is categorized into Quantitative ability, Reasoning, and Verbal Ability. Once the candidate qualifies the online round, they are advanced to the technical round. This round checks the conceptual background and technical perfection of a candidate. Questions are generally from various IT subjects. The recruitment process ends with the HR round. Questions regarding candidate curriculum vitae, job and company are generally asked in the HR round (Geeks for Geeks INFOSYS 2017). The main problems involved are listed as (Kumari and Kumari 2014):

(a) All graduate and post graduate students are eligible for recruitment and selection process if only they have secured 70 percentages of marks throughout.

(b) Student who has attended the recruitment process in the past 9 months are not eligible.

(c) Cost to hire is high.

(d) There is need of Psychometric test.

(e) Interviews are not based on specific skills. 
The Infosys employee retention scheme is not as good as the TCS plans, and therefore needs a change. Infosys has found it challenging to sustain a high level of employee engagement at all positions (Thimmaya 2014). It has been observed that many of the fresh graduates joining the organization leave the organization after a span of one or two years in order to pursue higher studies (Agrawal 2016). It is important to note that the employee is not leaving Infosys, they are generally parting away from their managers. In Infosys there exists a lack of organizational as well as operational clarity from upper-level managers. There exist rigidity and opaqueness in the organization due to the problems in the midst of higher ranked officials (Gadgets Now 2017; Rediff Business 2017). These problems also add to recruiting and retention issues (Jha 2014).

Solutions: Theories of HR management should concentrate more on the methodologies of recruitment and selection as well as focusing on the advantages of the interview, general assessment, and psychometric testing. The interview is an important criterion for selecting the right candidate for the specific area. Instead of asking questions from various fields, there should be a scheme to ask the question from a particular area, for example, Java, to the candidate who is proficient in Java. This way rightly qualified candidate will be selected and time consumption will be less. More stress should be given to psychometric test as this will help to give a better overall evaluation of a candidate and hopefully secure the best fit for the role. The recruitment process may be internal or external or may also be online. The incorporation of online interview scheme will facilitate a reduction in hiring cost. Much expenditure is involved in the external or internal recruitment process as the companies have to book large space for carrying out the recruitment process, which includes other maintenance costs. There should not be any benchmark, such as the 70 percent for selecting a candidate. The candidate may secure lower grades in the exam but he/she may excellent in particular IT skills which may solve the problem of skill shortages. Also, the duration scheme of 9 months is hinder for the recruitment of skilled employee. In India, there is a large number of private institutions which offers the crash course on Specific IT skills (AptechLearning 2017). In the duration of just 3-6 months, one individual can polish his skills on particular IT area. So this schedule of 9 months is not an appropriate means and possibly prevents talented individuals to be reconsidered. The policy of recruitment should be laid down without any time constraint. When an organization receives the bulk of applications for an advertised position, the significant approach should be to interview fewer candidates from the long list of candidates, which facilitate the screening of the applications to recruit the most appropriate candidates for interview. Instead of focusing on the logical and quantitative ability, more stress should be focused on the specific technical skills thus mitigating the problem of skill shortages. There is a requirement of the online screening process to select the suitable candidate for the right post. For the exam, if there is a requirement in the company in the area of $\mathrm{C}++$, then the candidates having proficiency only in that area should apply. There should be a mechanism for the candidate to prove their proficiency while filling the online application form for the interview process. The proof may be in terms of certificates from private training institutions validating expertness in the particular area of IT.

A proper retention scheme is essential to handle the situations related to employee retention. Superior strategic planning criteria should be applied to deal with the problem of employee retention. There should be a proper approach to provide higher education to the employee. The education like part-time management course or master degree in management while in the job will boost the moral and position of an employee. New training needs should be validated which includes equal opportunities, customer care, and communication. In Infosys, after the training exams are conducted and need to be passed by the employee in order to sustain jobs. So this approach has to be changed and better quality people with specific IT skills should be hired from the beginning, in order to avoid exams after training. 


\subsection{What Is Infosys Doing to Minimize Skill Shortage Problems?}

Infosys has developed a predictive tool in order to identify performers, compute organizational health as well as for searching and retaining talented employees. Infosys laid down an algorithm that can provide heads-up on the employee at the risk of attrition. This technique helps managers to make personalized retention solutions for employees. The technique of analytics is being used by Infosys managers in order to identify key talent. The analysis of identification is carried out on the basis of skills and experience point of view (Venkat 2016). Skill shortages are also dealt with by restructuring the variable pay program, stepping up promotions, ramping up of certification and training programs and a fast-track process for employees (CBSMOHALI 2017). While recruiting new employees, Infosys took adequate care to detect the right candidates. Infosys also emphasize recruiting the candidate who has a high degree of learning abilities. Infosys recently launched a program named "Pathfinder," which is based on career orientation (Rawat 2013).

\subsection{New HR Policies by Infosys to Mitigate Skill Shortages}

The Sustainability Report (2017) of Infosys reveals the new HR policies which may be very essential to mitigate the skill shortages problem. The policies are listed in a sequential manner as.

\subsubsection{Talent Strategy}

Infosys has launched a program named Zero Distance to bring innovation to every project and also provides the reward to the employees for their innovative work. This is a great program contributing towards employee retention. The program Compass was launched to mobilize career opportunities as well as learning and networks. This program supports employees to take their own decision and helps cultivate their particular skills. Another program named Accelerate helps the employees to sharpen their skill and experience database thus providing value through work.

\subsubsection{Talent Development and Diversity}

The leadership program named Leadership Blueprint is launched to develop leadership abilities using experimental learning via stretch roles and rotational programs. These schemes are intended towards personality development which is an important skill for an organization. Also, the Infy Makers Awards acknowledge the individual who has given innovative solutions to the real-world problems. Sapphire scheme is to facilitate expecting and young mothers to balance between personal commitments and work. This sort of schemes attracts more women to join the organization.

\subsubsection{Talent Management}

Infosys always emphasizes minimizing the number of part-time employees thus creating an atmosphere of superior job security. To strengthen the communication of employees in the organization, Infosys launched programs like Sparsh, InfyTV, and LITMUS. Proper communication facilities the retention of an employee in an organization. Schemes such as IGLU help to maintain decent and comfortable workplace for gay, lesbian and transgender communities. This is an important contribution towards the mitigation of skill shortages.

\subsubsection{Work-Life Balance and Continuous Improvement}

Infosys launched several schemes such as paid maternity leave, adoption leave, extended maternity leave, a sabbatical for higher education for creating a harmony between work and life thus improving the chances for retention and attracting employees. The continuous education program in Infosys related to technology and business process helps the employee to flourish in their skills and be updated with the current skills. The other schemes for continuous learning are the KM portal, Konnect, TeamWiki. Infosys also stress on higher education opportunities for the employees through Higher Education Support (HES) policy for enhancing the competency and qualifications of the employees. 
Infosys HR policies and other initiatives helping to mitigate the problem of skill shortages but not too considerable extent as literature suggest. So the solutions illustrated in this research should be added to the Infosys policies to mitigate the problem of skill shortages to a considerable extent. Infosys updated policies do not include psychometric tests, online interview scheme, and reduction in cutoff associated with the selection process. The following important points should be given due consideration:

(a) The predictive tools are developed to analyze the performance type attributes. It should also focus on the working environments and employee-management relation curve.

(b) Pathfinder is developed for career orientation but there is a need of developing a program to conduct a thorough analysis of employees on weekly basis in order to monitor personal problems, grievances, salary issues, and other social problems. This will help in the retention of the employees to the highest extent.

\section{Discussion}

TCS and Infosys should apply the technique of continuous working-learning process. There has to be some scheme for providing training on every Friday of a week to upgrade the employee knowledge with current trends. An employee working on the particular domain can be provided with more information and knowledge on the respective domain. This way the employee will not run out of trending skills thus contributing significantly to the organization. It is important to create a partnership with local or national educational facilities. TCS and Infosys should set up their training center inside the university or education facilities campus so as to train the students with the required skills for the organization. Hence, once they are out of University, they are ready to join the organization with updated skills. The approach of hiring contingent workers can deal with the problems of skill shortage in an efficient manner. Thus, recruiting freelancers, consultants, and contractors, it can fill massive gaps rapidly and in a cost-effective manner. In this approach, there is a need of quality control team in the IT organization to monitor and review the contribution of the contingent workers for proper growth of the organization and thus creating a sense of responsibilities towards the organization. The other general ways of handling skill shortages problem associated with recruitment and selection, retention scheme which is mentioned in the earlier section are:

- Grading of jobs.

- Properly fixing the rates of pay on the day of appointment.

- Increase of promotion opportunities.

- Reviews in terms of equal packages.

\section{Conclusions}

In this paper, the problems related to the skill shortages are analyzed and possible solutions are provided to deal with the problem of skill shortages in an effective manner. TCS and Infosys, the leading IT companies of India are taken as the case study for analysis. Various issues related to skill shortages such as recruitment and selection, employee retention, brain drain phenomena, employee compensation, reward management, employee training and geographical location are analyzed and the reason for these issues in incrementing skill shortage problems are laid down. Also, several solutions are illustrated for mitigating skill shortage problems in the IT industries. From the analysis, it is clear that, although TCS and Infosys are taking suitable measures for mitigating skill shortage problems, still many useful strategies needs to be implemented to minimize these problems to more extent. This research and analysis will help to handle the various problems embedded in the IT organization with a different and efficient approach. It will help the organization to find the right talent for the organization thus removing or decreasing the problem of skill shortages. This paper is an innovative approach for the proper functioning of the organization to great extent. Brain drain is a crucial phenomenon which is directly associated with skill shortages. So, the solutions provided 
in this research along with the current measures that the organizations following to minimize skill shortages will have a great effect on brain drain. The policies will compel the individual to return their home countries thus extracting privileges form the organization along with the comfortability of family members. This research is mainly intended towards the investigation of skill shortages in the IT industries of India. This research will help provide overview of why skill shortages exist in IT industries despite initiatives. It also highlights the current measures the IT industries are taking for curbing the skill shortages problem. Almost the same HR policies are followed in the organization involving the selection and retention of an employee. Even the brain drain phenomenon has the same impact on all type of industries. So, this research will not only help in mitigating skill shortages in TCS and Infosys, but it will help other organizations too in an effective manner. This research will highlight a path for other researchers, by giving them ideas of an approach and dealing skill shortages efficiently.

Funding: This research received no external funding.

Conflicts of Interest: The author declare no conflict of interest.

\section{References}

AbhiSaysINFOSYS. 2017. Office Locations of INFOSYS. Available online: http:/ /abhisays.com/ (accessed on 16 August 2017).

AbhiSaysTCS. 2017. Office Locations of TCS. Available online: http:/ /abhisays.com/ (accessed on 17 August 2017).

Acharya, Padmanav, and Biswajit Mahanty. 2007. Manpower shortage crisis in Indian information technology industry. International Journal of Technology Management 38: 235-47. [CrossRef]

Agrawal, Lipi. 2016. Infosys' Employee Retention Strategy: Proactive Not Reactionary. HRKatha. Available online: http:/ / www.hrkatha.com/infosys-employee-retention-strategy-proactive-not-reactionary/ (accessed on 15 February 2018).

Ahmad, Sohel, and Roger G. Schroeder. 2002. The importance of recruitment and selection process for sustainability of total quality management. International Journal of Quality \& Reliability Management 19: 540-50.

ALLENCOMM. 2017. Available online: http:/ /www.allencomm.com (accessed on 25 February 2018).

AptechLearning. 2017. Available online: http://www.aptech-education.com/about-us-overview (accessed on 18 September 2017).

Armstrong, Michael. 2007. A Handbook of Employee Reward Management and Practice. London and Sterling: Kogan Page Publishers, p. 548.

Ayyar, Ranjani. 2017. Five highest paying industry sectors in India. The Times of India, April 6.

Ayyar, Ranjani, and Sunitha Rao. 2017. Surging layoffs plunge techies into depression. The Times of India, July 17.

Baruch, Yehuda, Pawan S. Budhwar, and Naresh Khatri. 2007. Brain drain: Inclination to stay abroad after studies. Journal of World Business 42: 99-112. [CrossRef]

Basu, Sreeradha. 2016. IT highest-paying sector in India, manufacturing least: Study. The Economic Times, India, February 15.

Booth, Alison L., and Dennis J. Snower. 1996. Acquiring Skills: Market Failures, Their Symptoms and Policy Responses. Cambridge: Centre for Economic Policy Research (Great Britain), Cambridge University Press.

Brewster, Chris, Paul Sparrow, Guy Vernon, and Elizabeth Houldsworth. 2011. International Human Resource Management, 3rd ed. London: CIPD Publishing.

Bushnell, Peter, and Wai Kin Choy. 2001. Go West, Young Man, Go West? Treasury Working Paper 1/7; Wellington, New Zealand: THE TREASURY.

Bussiness Line. 2007. Retaining Talent, the TCS Way. Available online: http:/ / www.thehindubusinessline.com/ (accessed on 2 August 2017).

Careersnz. 2015. What Are Skill Shortages? Available online: https://www.careers.govt.nz/ (accessed on 14 March 2018).

Cascio, Wayne F., Ralph A. Alexander, and Gerald V. Barrett. 1988. Setting cutoff scores: Legal, psychometric, and professional issues and guidelines. Personnel Psychology 41: 1-24. [CrossRef]

CBSMOHALI. 2017. A Case of Infosys. Available online: http:/ / www.cbsmohali.org/ (accessed on 12 March 2018). 
Clarke, Linda, and Georg Herrmann. 2007. Skill shortages, recruitment and retention in the house building sector. Personnel Review 36: 509-27. [CrossRef]

Cohen, Malcolm S., and Mahmood A. Zaidi. 2002. Global Skill Shortages. Cheltenham: Edward Elgar Publishing.

Corporate Sustainability Report. 2017. Tata Consultancy Services. Available online: https://www.tcs.com/ content/dam/tcs/ (accessed on 7 April 2018).

Diffrenceinmajoritindustries. 2011. Infosys vs. Wipro vs. TCS: Which Is Better? Available online: http:// diffrenceinmajoritindustries.blogspot.com/ (accessed on 9 November 2017).

Dobbs, Michael E. 2014. Guidelines for applying Porter's five forces framework: A set of industry analysis templates. Competitiveness Review 24: 32-45. [CrossRef]

Dowling, Peter J., Marion Festing, and Allen D. Engle Sr. 2008. International Human Resource Management. Boston: Cengage Learning.

Fournier, Julia. 2017. 5 Ways Companies Can Address a Skills Shortage. Available online: https:/ / www.hcmworks. com/blog (accessed on 3 March 2018).

Freifeld, Lorri. 2017. Bridging the Skills Gap. Available online: https:/ / trainingmag.com/ (accessed on 7 May 2018).

Gadgets Now. 2017. 7 Biggest Issues Causing Tussle between Infosys and the Company's Founders. Available online: http:/ / www.gadgetsnow.com/ (accessed on 23 April 2018).

Geeks for Geeks INFOSYS. 2017. INFOSYS Recruitment Process. Available online: http:/ / www.geeksforgeeks. org/ (accessed on 1 March 2018).

Geeks for Geeks TCS. 2017. TCS Recruitment Process. Available online: http:/ / www.geeksforgeeks.org/ (accessed on 9 May 2018).

Green, Francis, and David Ashton. 2016. Skill Shortage and Skill Deficiency: A Critique. Work, Employment and Society 6: 287-301. [CrossRef]

Grundy, Tony. 2006. Rethinking and reinventing Michael Porter's five forces model. Strategic Change 15: 213-29. [CrossRef]

Haskel, Jonathan, and Christopher Martin. 1993. Do Skill Shortages Reduce Productivity? Theory and Evidence from the United Kingdom. The Economic Journal 103: 386-94.

Haskel, Jonathan, and Christopher Martin. 2001. Technology, Wages, and Skill Shortages: Evidence from UK. Micro Data, Oxford Economic Papers 53: 642-58. [CrossRef]

Holt, Richard, Szymon Sawicki, and James Sloan. 2010. A Theoretical Review of Skill Shortages and Skill Needs; Evidence Report 20; Rotherham: UKCES.

Hughey, W. Aaron, and Kenneth J. Mussnug. 1997. Designing effective employee training programmes. Training for Quality 5: 52-57. [CrossRef]

Infosys. 2017. Being Infosys. Being More. Annual Report 2015-2016. Bengaluru: Infosys.

Infosys Training. 2013. Fresher Queries. Available online: http://infosystrainings.blogspot.mx/ (accessed on 16 April 2018).

INFOSYS Wiki. 2018. Available online: https:/ / en.wikipedia.org/wiki/Infosys (accessed on 17 July 2017).

Interband Report. 2016. Best Indian Brands 2016. Available online: http:/ / brandequity.economictimes (accessed on 22 February 2018).

Iresearchnet. 2015. Employee Selection, Psychology. Available online: https://psychology.iresearchnet.com/ (accessed on 17 March 2018).

Iskandar, Basel. 2015. Aims \& Objectives of Reward Management. Available online: https://www.linkedin.com/ pulse/ (accessed on 19 November 2017).

Jha, Aditya Nath. 2014. The REAL Problem of Infosys. LinkedIn. Available online: https:/ /www.linkedin.com/ (accessed on 14 May 2018).

Johanette Rheeder. 2017. Legal Aspects in Recruitment and Selection. Johanette Rheeder Incorporated. Available online: https:/ / www.jrattorneys.co.za/ (accessed on 25 June 2018).

Jose, Diya. 2013. What Are the Top 5 Employee Retention Strategies? Available online: https:/ /blog.synergita. com/ (accessed on 16 July 2017).

Jozwiak, Gabriella. 2014. Skills shortage vacancies' rise twice as fast as available jobs. HR, January 30.

Kapur, Devesh. 2017. Addressing the brain drain: A partial cosmopolitanism approach. South African Journal of Philosophy 36: 45-57. [CrossRef]

Kerr, Jeffrey, and John W. Slocum Jr. 1987. Managing corporate culture through reward systems. The Academy of Management Executive 1: 99-108. 
Kochan, Thomas A., David Finegold, and Paul Osterman. 2012. Who Can Fix the "Middle-Skills" Gap? Harvard Business Review, December 1.

Krishnan, Ravi. 2016. Cyrus Mistry vs Ratan Tata: A guide to the key issues involved. Livemint, October 27. Available online: https:/ / www.livemint.com/Companies/0F1R1KoI1wugK6jq9r1ZFK/The-TataMistryspat-All-you-need-to-know.html (accessed on 12 December 2017).

Kumari, Sunidhi, and Nivedita Kumari. 2014. Recruitment Process of Infosys. Slide Share, November 4. Available online: https://www.slideshare.net/sunidhikumari1/recruitment-process-of-infosi (accessed on 14 December 2017).

Kurup, Rajesh, and N. S. Vageesh. 2017. Business Line. Available online: http:/ /www.thehindubusinessline.com/ (accessed on 21 March 2018).

Leuven, Edwin, Hessel Oosterbeek, and Hans Van Ophem. 2004. Explaining international differences in male skill wage differentials by differences in demand and supply of skill. Economic Journal 114: 466-95. [CrossRef]

Livingston, Gillian. 2013. Five ways companies can address a shortage of skills. The Globe and Mail, April 29.

Mayhew, Ruth. 2017. How Does a Massive Hiring Affect an HR Department? Chron. Available online: https: / / smallbusiness.chron.com/massive-hiring-affect-hr-department-48450.html (accessed on 4 June 2018).

McMullin, Julie Ann, Martin Cooke, and Rob Downie. 2004. Labour Force Ageing and Skill Shortages in Canada and Ontario. Toronto: Longwoods.

MindTools. 2018. Understanding Competitive Forces to Maximize Profitability. Porter's Five Forces. Available online: https: / www.mindtools.com/ (accessed on 22 December 2017).

MSG. 2017. Employee Retention. Available online: http://www.managementstudyguide.com (accessed on 12 October 2017).

Mukunthan, Athreya, and Eashwar Nagaraj. 2017. The Great Indian Brain Drain, and Nothing to Come Back To. The Quint, July 16.

Murti, Ashutosh Bishnu, and Paul G. D. Bino. 2014. Determinants of Skill Shortages in Indian Firms: An Exploration. Indian Journal of Industrial Relations 49: 439-55.

OECD. 2008. Economic Surveys: Czech Republic. Paris: OECD.

Olivia. 2011. Difference between Infosys and TCS. Difference Between. Available online: http://www. differencebetween.com/ (accessed on 12 January 2018).

Patel, Chirag. 2013. TCS Recruitment and Selection. Slide Share, March 19. Available online: https://www. slideshare.net/Erchiragpatel/tcs-recruitment-and-selection (accessed on 12 June 2018).

Patel, Nevil. 2014. TCS ILP Training—Procedure. Experience and Facilities. Available online: https://www. technonutty.com (accessed on 9 April 2018).

Playfair, Eddie. 2016. Skill Shortage, Training Shortage or Job Shortage? Available online: https:/ / eddieplayfair. com/ (accessed on 19 September 2017).

Quora. 2016. Does TCS Consider Candidate's Location Preference after Training? Available online: https: / / www.quora.com (accessed on 19 September 2017).

Quora. 2017. What Is the Training Process for TCS? Available online: https:/ wwww.quora.com (accessed on 22 March 2018).

Rawat, RashmiBadjatya. 2013. Emerging Employee Retention Strategies in IT Industry. Pioneer Journal, April 30.

Recomparison. 2017. Difference between Infosys, Wipro and TCS. Available online: http:/ / recomparison.com/ (accessed on 21 January 2018).

Rediff Business. 2017. What Really Is the Problem at Infosys? Available online: http:/ / www.rediff.com/ (accessed on 19 October 2017).

Richardson, Sue. 2007. What Is a Skill Shortage? Australia: National Centre for Vocational Education Research (NCVER).

Roberts, Gareth. 1997. Recruitment and Selection: A Competency Approach. Developing Practice. London: CIPD Publishing.

Sarma, Mahesh, and Venni Venkata Krishna. 2010. State and the software: Public policies in the shaping of the Indian software sector. The Service Industries Journal 30: 25-42. [CrossRef]

Saurabh, Prabhu. 2016. Peer Comparison-Infosys vs TCS vs Wipro. Just Another Investor, August 13.

Saxenian, AnnaLee. 2005. From Brain Drain to Brain Circulation: Transnational Communities and Regional Upgrading in India and China. Studies in Comparative International Development 40: 35-61. [CrossRef]

Shah, Aditi. 2016. Tata's boardroom battle with ousted chairman Mistry escalates. Reuters, November 11.

Singh, Shreyasi. 2013. Can India Plug Its Brain Drain? The Diplomat, September 5. 
Singh, Nirvikar. 2016. Information Technology and its Role in India's Economic Development: A Review. India: Development in India. New Delhi: Development in India.

Singh, Jaspertap, and Venni Venkata Krishna. 2015. Trends in Brain Drain, Gain and Circulation: Indian Experience of Knowledge Workers. Science, Technology and Society 20: 300-21. [CrossRef]

Sinha, Varun. 2015. Why More Employees are Quitting TCS than Ever Before. NDTV Profit, July 10.

Sites TCS. 2017. Available online: http://sites.tcs.com/community/100000-women.html (accessed on 19 February 2017).

Sparrow, Paul R., and Jean-M. Hiltrop. 1994. European Human Resource Management in Transition 1994. New York: Prentice Hall.

Stevens, Philip Andrew. 2007. Skill shortages and firms' employment behavior. Labour Economics 14: $231-49$. [CrossRef]

StudAids. 2013. HRM Strategies for Overcoming Skill Shortages within the UK Manufacturing Industry. A Study of Leyland Trucks \& AESSEAL. Walsall: Study-Aids.

Study.com. 2017. What Is Employee Compensation?-Definition \& Concept. Available online: http://study.com/ (accessed on 22 October 2017).

TCS Wiki. 2018. Available online: https://en.wikipedia.org/wiki/Tata_Consultancy_Services (accessed on 25 June 2018).

Thimmaya, Poojary. 2014. TCS miles ahead of Infosys in retaining employees. Financial Express, April 20.

UK Essays. 2015. Recruitment Methods at Tata Consultancy. Available online: https://www.ukessays.com/ (accessed on 17 September 2017).

Varma, Gedela Rakesh, and Jaladi Ravi. 2017. Training and Development in MNC: A Case Study on Infosys, International Journal and Magazine of Engineering, Technology. Management and Research 4: 499-505.

Venkat, Apurva. 2016. Infosys builds tool to predict attrition, help in retaining top talent. Business Standard, August 12.

Venkatesh, Shruti. 2017. Samsung is India's most trusted brand. Report India Forbes, April 6.

Walters, Robert. 2016. How to Retain Staff and Avoid Talent Shortages. Available online: https://www. robertwalters.co.uk (accessed on 12 August 2017).

Xiang, Biao. 2001. Structuration of Indian information technology professionals' migration to Australia: An ethnographic study. International Migration 39: 73-90. [CrossRef]

Zagade, Aatish, and Supriya P. Desai. 2017. Brain Drain or Brain Circulation: A Study of Returnee Professionals in India. Journal of Commerce E Management Thought 8: 422-35.

(C) 2018 by the author. Licensee MDPI, Basel, Switzerland. This article is an open access article distributed under the terms and conditions of the Creative Commons Attribution (CC BY) license (http://creativecommons.org/licenses/by/4.0/). 